This is an electronic reprint of the original article. This reprint may differ from the original in pagination and typographic detail.

Author(s): Moilanen, Jani; Day, Benjamin M.; Pugh, Thomas; Layfield, Richard A.

Title: $\quad$ Open-shell doublet character in a hexaazatrinaphthylene trianion complex

Year: $\quad 2015$

Version:

Please cite the original version:

Moilanen, J., Day, B. M., Pugh, T., \& Layfield, R. A. (2015). Open-shell doublet character in a hexaazatrinaphthylene trianion complex. Chemical Communications, 51(57), 11478-11481. https://doi.org/10.1039/C5CC04004C

All material supplied via JYX is protected by copyright and other intellectual property rights, and duplication or sale of all or part of any of the repository collections is not permitted, except that material may be duplicated by you for your research use or educational purposes in electronic or print form. You must obtain permission for any other use. Electronic or print copies may not be offered, whether for sale or otherwise to anyone who is not an authorised user. 


\title{
Open-Shell Doublet Character in a Hexaazatrinaphthylene Trianion Complex $\dagger$
}

\author{
Jani O. Moilanen, ${ }^{a, b}$ Benjamin M. Day, ${ }^{a}$ Thomas Pugh ${ }^{a}$ and Richard A. Layfield $*^{a}$
}

Received 00th January 2012,

Accepted 00th January 2012

DOI: $10.1039 / \times 0 \times x 00000 x$

www.rsc.org/

Three-electron reduction of hexaazatrinaphthylene (HAN) with a magnesium(I) reagent leads to [(HAN) $\left\{\mathrm{Mg}(\right.$ nacnac $\left.) \boldsymbol{\}}_{3}\right]$ (1), containing a [HAN] ${ }^{3-}$ ligand with a spin of $S=1 / 2 . A b$ initio calculations reveal that the $[\mathrm{HAN}]^{3-}$ ligand in 1 has a groundstate wave function with multiconfigurational properties, and can be described as a triradicaloid species with a small amount of open-shell doublet character.

Hexaazatriphenylene (HAT) and related aromatic compounds have unusual molecular and electronic structure properties including: a disk-like shape; rigid three-fold symmetry; the ability to bind up to three metal ions; and rich electrochemistry due to the presence of low-lying $\pi^{*}$ orbitals. ${ }^{1}$ HAT and related compounds have been used as building blocks in supramolecular coordination compounds, ${ }^{2-4}$ and their metal complexes have been studied for their photophysical properties, such as charge transfer and fluorescence sensing. ${ }^{5-7}$ Metal-free HAT derivatives can display liquid crystal behaviour, ${ }^{8}$ which, in tandem with their electron transport and semiconductor properties, $^{9}$ has introduced potential uses in organic electronics. ${ }^{10-15}$ Electron-deficient HAT derivatives have also been used for anion recognition applications. ${ }^{16}$

The ability of HAT-type ligands to bind up to three transition metal ions is of interest in the context of molecular magnetism. The HAT $\pi$-system can provide exchange coupling pathways between paramagnetic centres, and the $C_{3}$-symmetry relationship between the coordination pockets introduces the possibility of spin frustration or non-collinearity. Such situations have been considered in HAT complexes of iron and cobalt, however the exchange coupling is typically weak, and frustrated magnetism has not yet been observed. ${ }^{17-19}$

A potential method for strengthening the magnetic communication between metal ions in HAT complexes ligands is to reduce the heterocycle to one of its corresponding anions, e.g. $[\mathrm{HAT}]^{n-}$, where $n=1,2$ or 3 . Several trimetallic complexes of the formally mono-anionic hexacyano-HAT ligand, $\left[\mathrm{HAT}(\mathrm{CN})_{6}\right]^{-}$, have been characterized by crystallography and EPR spectroscopy, with the latter technique providing evidence for organic radicals with $S=1 / 2 .{ }^{1,2}$ Two-electron reduction of HAT can give spin configurations of $S=0$ or $S=1$, and the sole example of a HAT dianion, $\mathrm{K}_{2}\left[\mathrm{HAT}(\mathrm{CN})_{6}\right]$, was shown by EPR spectroscopy to be a spin triplet. ${ }^{20}$

In the case of three-electron reduction, HAT-type trianions can, in principle, occur with a ground-state spin of $S=1 / 2$ or $S=$ $3 / 2$. To the best of our knowledge, a HAT trianion has not previously been reported, and we were therefore interested in isolating such a species in order to study its electronic structure. For ease of synthesis (i.e. avoiding use of explosive precursor materials), we selected the extended derivative hexaazatrinaphthylene (HAN). To synthesize a soluble trimetallic complex of $[\mathrm{HAN}]^{3-}$, such that a crystallographic study of the molecular structure could be undertaken, we chose to reduce HAN with the magnesium(I) reagent $[\mathrm{Mg}(\text { nacnac })]_{2}$, where nacnac $=N, N^{\prime}$-(2,6-diisopropylphenyl)-3,5dimethyldiketiminate. $^{21}$ This strategy allowed access to $\left[(\mathrm{HAN})\{\mathrm{Mg}(\text { nacnac })\}_{3}\right]$.toluene (1-toluene), which was isolated in a yield of $64 \%$ (Scheme 1 ).

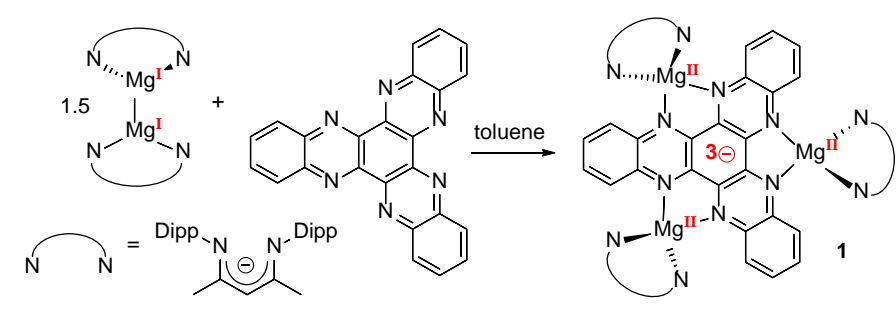

Scheme 1. Synthesis of $\mathbf{1}$ (Dipp = 2,6-diisopropylphenyl).

Compound 1-toluene crystallizes in the $P 6_{3} / m$ space group (Table S1), with the crystallographic 3- and 6-fold rotation axes passing through the centre of, and perpendicular to, the HAN heterocycle. A mirror plane coincides with the plane of the $[\mathrm{HAN}]^{3-}$ ligand and the magnesium centres. The symmetryrelated magnesium atoms in $\mathbf{1}$ occupy distorted tetrahedral environments, with $\mathrm{N}-\mathrm{Mg}-\mathrm{N}$ angles in the range 81.21(9)$125.23(6)^{\circ}$ (average $109.6^{\circ}$ ). The $\mathrm{Mg}(1)-\mathrm{N}(1)$ and $\mathrm{Mg}(1)-\mathrm{N}(2)$ bond lengths to the HAN ligand are 2.076(2) and 2.071(2) $\AA$, respectively (Figures 1 and S3). The $\mathrm{Mg}(1)-\mathrm{N}(3)$ bond lengths to the nacnac ligands are $2.0438(18) \AA$, hence they are shorter 
than the Mg-N(HAN) bond lengths by about $0.03 \AA$, presumably due to stronger electrostatic bonding. The $\mathrm{C}-\mathrm{N}$ bond lengths within the $[\mathrm{HAN}]^{3-}$ ligand of $\mathbf{1}$ are 1.359(3)1.391(3) $\AA$ (average $1.374 \AA$, range $0.032 \AA$ ); the $\mathrm{C}-\mathrm{C}$ bond lengths are 1.407(4)-1.440(4) $\AA$ (average $1.420 \AA$, range 0.033 $\AA$ ). In comparison, the $\mathrm{C}-\mathrm{N}$ and $\mathrm{C}-\mathrm{C}$ bond lengths in $\mathrm{HAN} \cdot 4\left(\mathrm{CHCl}_{3}\right)$ are $1.318(5)-1.382(5) \AA$ (average $1.342 \AA$, range $0.064 \AA$ ) and 1.347(6)-1.491(6) $\AA$ (average $1.411 \AA$, range $0.144 \AA) .^{22}$ Thus, although the average HAN bond lengths in $\mathbf{1}$ and in HAN are similar, those in $\mathbf{1}$ fall in much narrower ranges, particularly the $\mathrm{C}-\mathrm{C}$ bonds.

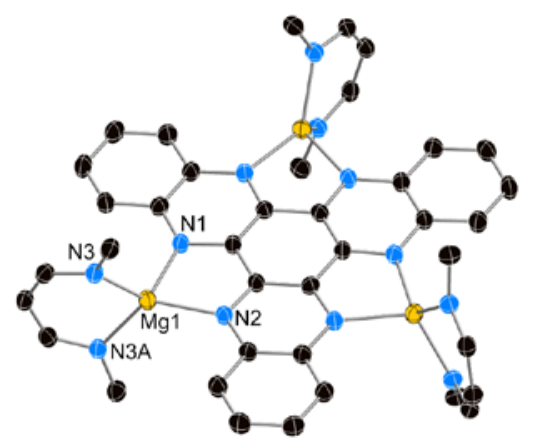

Figure 1. Thermal ellipsoid representation (50\% probability) of the structure of 1 For clarity, the 2,6-Dipp substituents have been removed and only the ipso aryl carbons are shown. The methyl groups and hydrogen atoms are not shown.

The X-band EPR spectrum of 1-toluene was recorded at $293 \mathrm{~K}$ in the solid state and in solution. Both measurements feature a broad singlet with $g_{\text {iso }}=2.003$ (Figure S4), which is typical of an organic radical with $S=1 / 2$. No evidence for any other paramagnetic species was found. The UV/vis/NIR absorption spectrum of $\mathbf{1}$-toluene in thf in the range $\lambda=300-2000 \mathrm{~nm}$ features a main peak at $338 \mathrm{~nm}$ with shoulders at 390, 417, 460, 496 and $563 \mathrm{~nm}$ (Figure 2). Two weaker, broad absorptions were observed at $808 \mathrm{~nm}$ and $909 \mathrm{~nm}$, and four weak absorptions at 1210, 1346, 1493 and $1633 \mathrm{~nm}$ were also found.

Further insight into the EPR and electronic absorption spectra was obtained by analysing the electronic structure of 1.toluene using density functional theory (DFT). To simplify the calculations, the methyl substituents on the nacnac backbone were replaced with hydrogen atoms, as were the isopropyl groups on the 2,6-Dipp substituents. The geometries of this model system, 1a, were optimized for the two possible spin configurations $S=1 / 2$ and $S=3 / 2$, with $C_{1}$ and $C_{3}$ point symmetry, respectively. ${ }^{23}$ The calculations used the B3LYP functional with 6-311G** and def2-TZVP basis sets. ${ }^{24-26}$

The geometry optimizations yielded structures for 1a with $S$ $=1 / 2$ and $S=3 / 2$ that both closely match the experimental structure of 1 (Figures S5 and S6, and Tables S2 and S3). Using the $6-311 \mathrm{G}^{* *}$ basis set, the $S=1 / 2$ form of 1 a was calculated to be the ground state and, although this result is consistent with the EPR spectrum of 1 , the $S=3 / 2$ form is only $9.4 \mathrm{~kJ} \mathrm{~mol}^{-1}$ less stable $\left(12.0 \mathrm{~kJ} \mathrm{~mol}^{-1}\right.$ using def2-TZVP). Hence, the electronic ground state of $[\mathrm{HAN}]^{3-}$ cannot be assigned unambiguously on the basis of the geometry optimizations because the relative energies of different spin configurations can be poorly described by DFT. ${ }^{27}$

Further support for the assignment of the $S=1 / 2$ configuration to $\mathbf{1}$ was obtained from a time-dependent DFT study of 1a. A single-point TD-DFT calculation was performed using the B3LYP/6-311G** optimized geometry at the CAMB3LYP/6-31+G*/THF level of theory (Figures 2 and S7, and Tables S4 and S5). The calculated electron excitations for 1a with $S=1 / 2$ produced a spectrum that closely matches the experimentally observed spectrum of 1 (Figure 2). The calculated electron excitations in the range $\lambda=300-400 \mathrm{~nm}$ correspond to the main absorption at $338 \mathrm{~nm}$ and its associated shoulder peaks in the experimental spectrum. These transitions represent transitions from lower-lying doubly occupied MOs of $[\mathrm{HAN}]^{3-}$ to the LUMO and to higher-lying orbitals, and from the SOMO to other higher-lying unoccupied orbitals. The absorptions in the NIR region correspond to transitions from the HOMO and SOMO to the lowest unoccupied MOs. For comparative purposes, the electronic spectrum of the $S=3 / 2$ form of 1a was also calculated: the calculated electron excitations for $S=3 / 2$ HAN occur at $\lambda=344-442 \mathrm{~nm}$, with no absorptions at longer wavelengths (Figure S7 and Table S5).
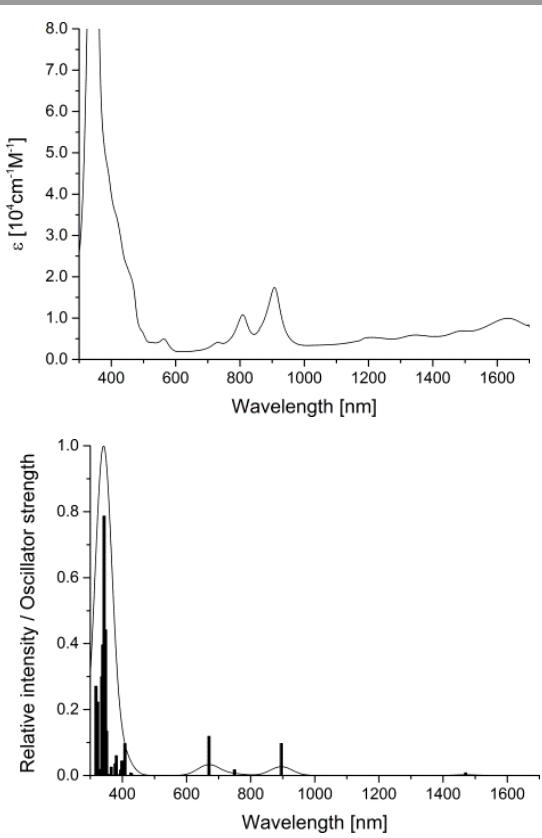

Figure 2. Upper: electronic absorption spectrum of 1-toluene in THF. Lower: simulated electronic spectrum for the model compound $\mathbf{1 a}$.

The frontier MOs, spin density and isotropic hyperfine coupling constants of the doublet form of 1a were calculated with DFT. Multiple small hyperfine coupling constants were calculated for 1a (Table S3) which, together with the broad spectral linewidth, mask all the characteristic hyperfine information in the EPR spectrum. The three-electron reduction of HAN distorts the planar geometry and lifts the degeneracy of the formally unoccupied MOs 101 and 102 in HAN (Figure S9). This structural distortion results in the spin density being distributed only across the $[\mathrm{HAN}]^{3-}$ ligand, i.e. it does not extend to the magnesium centres or to the nacnac ligands (Figure S6). Thus, taking into account the experimental and the computational data, 1a (and 1) can be regarded as an organic $\pi$ type radical with a doublet ground state.

The small calculated doublet-quartet separations for $\mathbf{1 a}$ and the small differences in energy between the frontier orbitals of the $S=1 / 2$ form, combined with the moderate HOMO-LUMO gap $(\sim 1.3 \mathrm{eV})$, prompted us to investigate the possibility of 
multiconfigurational character in the ground-state wave function. Thus, single-point complete active space (CAS) calculations were performed on 1a using the B3LYP/6-311G** optimized geometry and four active spaces. ${ }^{28}$ The calculated natural orbital occupation numbers (NOONs) at the CAS level of theory provide a benchmark of multi-configurational character (Table 1): NOONs of greater than 0.1 imply multiconfigurational character. ${ }^{29}$ The calculations reveal that there is a strong electron transfer effect from the formally occupied orbital 292 to the formally unoccupied orbital 294, which corresponds to 0.34 electrons using the largest active space of CAS $(9,9)$ (Table 1 ). This result indicates that multiconfigurational character plays a large role in the groundstate wave function of 1a. Inspecting the configurations and their coefficients within the CAS wave functions reveals that

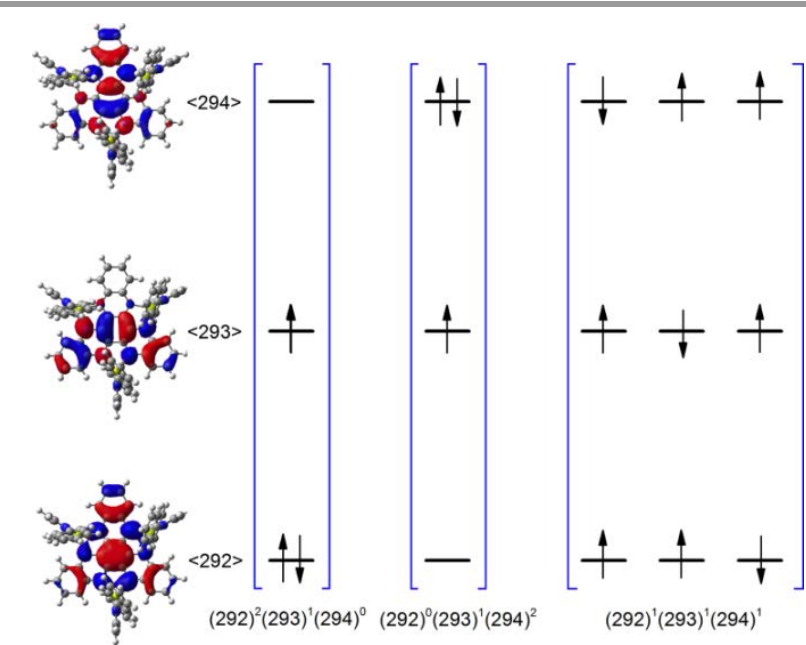

Figure 3. Frontier MOs and main electronic configurations of 1 a with $S=1 / 2$, calculated at the $\operatorname{CAS}(7,7)$ level of theory.

the ground state of 1a is mainly represented by a linear combination of five Slater determinants. These five determinants result in the Hartree-Fock configuration $(292)^{2}(293)^{1}(294)^{0}$, the excited configuration $(292)^{0}(293)^{1}(294)^{2}$ (in which two electrons are excited from orbital 292 to orbital 294) and the excited triradical configuration $(292)^{1}(293)^{1}(294)^{1}$ (in which one electron is excited from orbital 292 to orbital 294). These configurations account for $73 \%, 10 \%$, and $9 \%$, respectively, of the groundstate CAS $(7,7)$ wave function (Figure 3 and Table S6).

Table 1. Natural orbital occupation numbers (NOONs) for 1a with $S=1 / 2$.

\begin{tabular}{|c|c|c|c|c|}
\hline Orbital & CAS(3,3) & CAS(5,5) & CAS(7,7) & CAS(9,9) \\
\hline 289 & & & & 1.97 \\
\hline 290 & & & 1.98 & 1.96 \\
\hline 291 & & 1.97 & 1.96 & 1.95 \\
\hline 292 & 1.60 & 1.61 & 1.64 & 1.67 \\
\hline 293 & 1.00 & 1.00 & 1.00 & 1.00 \\
\hline 294 & 0.40 & 0.39 & 0.36 & 0.34 \\
\hline 295 & & 0.04 & 0.04 & 0.05 \\
\hline 296 & & & 0.03 & 0.05 \\
\hline 297 & & & & 0.03 \\
\hline
\end{tabular}

The triradical configuration in 1a arises from linear combinations of three Slater determinants, where the three components differ only in the spin state of the electrons (i.e. $\alpha \alpha \beta, \alpha \beta \alpha$ and $\beta \alpha \alpha$ ) (Figure 3). This observation indicates that $\mathbf{1}$ is a rare example of an organic open-shell doublet. Although the $[\mathrm{HAN}]^{3-}$ ligand is not strictly a triradical it can be said to possess a degree of $\pi \pi \pi$-triradicaloid character, which is consistent with the definition of triradicals being species that possess three (near-) degenerate orbitals containing three electrons, and a small doublet-quartet splitting. ${ }^{30}$

Organic triradicals are of interest owing to their unusual electronic structure and for their potential applications in organic magnetic materials. ${ }^{30-33}$ Notable examples include tridehydrobenzenes, dehydrophenylnitrenes, dehydryo- $m$ xylylenes and 1,3,5-trimethylenebenzene. The multiconfigurational character in $\mathbf{1}$ is reminiscent of that calculated for the fleeting $\left[\mathrm{S}_{3} \mathrm{~N}_{3}\right]^{\bullet}$ radical. ${ }^{34}$ In addition to the similarities in their open-shell doublet nature, organic triradicals are characterized by their highly reactive nature, which means that the experimental systems tend to be studied using matrix isolation techniques at cryogenic temperatures, or via gas-phase mass spectrometry. ${ }^{31-33}$ Complex $\mathbf{1}$ is therefore noteworthy because it is a stable, isolable material. ${ }^{35}$

In summary, [(HAN) $\left.\{\mathrm{Mg}(\text { nacnac })\}_{3}\right]$.toluene (1-toluene) was found to contain a $[\mathrm{HAN}]^{3-}$ ligand, i.e. the first trianionic derivative of a HAT-type ligand. EPR spectroscopy indicated that $[\mathrm{HAN}]^{3-}$ is an organic radical with $S=1 / 2$, and support for this assignment was provided by electronic spectroscopy on $\mathbf{1}$ and DFT calculations on the model compound 1a. CAS calculations show that 1a and, by implication, $\mathbf{1}$ is an open-shell doublet with a small amount of triradicaloid character. It should be possible to extend the method used to synthesize $[\mathrm{HAN}]^{3-}$ to other members of the HAT family. It should also be possible to transfer $[\mathrm{HAN}]^{3-}$ from magnesium to transition metals or lanthanides, and hence to study how the radical ligand influences exchange interactions between paramagnetic ions.

\section{Notes and references}

${ }^{a}$ School of Chemistry, The University of Manchester, Oxford Road, Manchester, M13 9PL, U.K.

E-mail: Richard.Layfield@manchester.ac.uk.

${ }^{b}$ Department of Chemistry, University of Jyvaskala, Jyvaskala, P.O. Box 35, FI-40014, Finland.

$\dagger$ Dedicated to Prof. Dr. Manfred Scheer on the occasion of his $60^{\text {th }}$ birthday.

Electronic Supplementary Information (ESI) available: synthesis, crystallographic, spectroscopic and computational details. See DOI: $10.1039 / \mathrm{c} 000000 \mathrm{x} /$

1 S. Kitagawa, S. Masaoka, Coord. Chem. Rev. 2003, 246, 73.

2 a) D. Tanaka, S. Masaoka, S. Horike, S. Furukawa, M. Mizuno, K. Endo, S. Kitagawa, Angew. Chem. Int. Ed. 2006, 45, 4628. b) S. Furukawa, T. Okubo, S. Masaoka, D. Tanaka, H. C. Chang, S. Kitagawa, Angew. Chem. Int. Ed. 2005, 44, 2700. c) T. Okubo, S. Kitagawa, M. Kondo, H. Matsuzaka, T. Ishii, Angew. Chem. Int. Ed. 1999, 38, 931. d) S. Masaoka, D. Tanaka, H. Kitahata, S. Araki, R. Matsuda, K. Yoshikawa, K. Kato, M. Takata, S. Kitagawa, J. Am. Chem. Soc. 2006, 128, 15799.

3 a) I. M. Piglosiewicz, R. Beckhaus, W. Saak, D. Haasse, J. Am. Chem. Soc. 2005, 127, 14190. b) I. M. Piglosiewicz, R. Beckhaus, G. Wittstock, W. Saak, D. Haasse, Inorg. Chem. 2007, 46, 7610.

4 S. Roy, B. Sarkar, C. Duboc, J. Fielder, O. Sarper, F. Lissner, S. M. Mobin, G. K. Lahiri, W. Kaim, Chem. Eur. J. 2009, 15, 6932. 
5 a) J. M. Herrera, S. J. A. Pope, A. J. H. M. Meijer, T. L. Easun, H. Adams, W. Z. Alsindi, X. Z. Sun, M. W. George, S. Faulkner, M. D. Ward, J. Am. Chem. Soc. 2007, 129, 11491. b) J. M. Herrera, E. Colacio, C. Mathonière, D. Choquesillo-Lazarte, M. D. Ward Chem. Commun. 2008, 4460.

6 a) W. Vanderlinden, M. Blunt, C. C. David, C. Moucheron, A. Kirsch-De Mesmaeker, S. De Feyter, J. Am. Chem. Soc. 2012, 134, 10214. b) B. Elias, A. Kirsch-De Mesmaeker, Coord. Chem. Rev. 2006, 250, 1627.

7 X. H. Hong, Q. Zhao, X. M. Liu, T. L. Hu, J. Han, W. J. Ruan, X. H. Bu, Talanta 2013, 108, 150.

8 a) V. Lemaur, D. A. da Silva Filho, V. Coropceanu, M. Lehmann, Y. Geerts, J. Piris, M. G. Debije, A. M. van de Craats, K. Senthilkumar, L. D. A. Siebbels, J. M. Warren, J. L. Brédas, J. Cornil, J. Am. Chem. Soc. 2004, 126, 3271. b) J. Cornil, V. Lemaur, J. P. Calbert, J. L. Brédas, Adv. Mater. 2002, 14, 726.

9 a) L. M. Klivansky, D. Hanifi, G. Koshkakaryan, D. R. Holycross, E. K. Gorski, Q. Wu, M. Chai, Y. Liu, Chem. Sci. 2012, 3, 2009. b) T. Aoki, H. Sakai, K. Ohkubo, T. Sakanoue, T. Takenobu, S. Fukuzumi, T. Hasobe, Chem. Sci. 2015, 6, 1498.

10 R. Juárez, M. Moreno Oliva, M. Ramos, J. L. Segura, C. Alemán, F. Rodriguez-Ropero, D. Curcó, F. Montilla, V. Coropceanu, J. L. Brédas, Y. Qi, A. Kahn, C. Ruiz Delgado, J. Casado, J. T. López Navarette, Chem. Eur. J. 2011, 17, 10312.

11 S. Barlow, Q. Zhang, B. R. Kaafarani, C. Risko, F. Amy, C. K. Chan, B. Domercq, Z. A. Starikova, M. Y. Antipin, T. V. Timofeeva, B. Kippelen, J. L. Brédas, A. Kahn, S. R. Marder, Chem. Eur. J. 2007, 13, 3537.

12 M. Wang, Y. Li, H. Tong, Y. Cheng, L. Wang, X. Jing, F. Wang, Org. Lett. 2011, 13, 4378.

13 C. H. Park, H. J. Lee, J. H. Hwang, K. N. Kim, Y. S. Shim, S. G. Jung, C. H. Park, Y. W. Park, B. K. Ju, ACS Appl. Mater. Interfaces 2015, 7, 6047.

14 Y. Ma, Y. H. Chung, L. Zheng, D. Zhang, X. Yu, L. Xiao, Z. Chen, S. Wang, B. Qu, Q. Gong, D. Zou, ACS Appl. Mater. Interfaces 2015, 7, 6406.

15 H. Sun, Q. Guo, D. Yang, Y. Chen, J. Chen, D. Ma, ACS Photonics 2015, 2, 271.

16 a) G. Aragay, A. Frontera, V. Lloveras, J. Vidal-Gancedo, P. Ballester, J. Am. Chem. Soc. 2013, 135, 2620. b) H. T. Chifotides, B. L. Schottel, K. R. Dunbar, Angew. Chem. Int. Ed. 2010, 49, 7202. c) H. T. Chifotides, K. R. Dunbar, Acc. Chem. Res. 2013, 46, 894.

17 S. R. Marshall, A. L. Rheingold, L. N. Dawe, W. W. Shum, C. Kitamura, J. S. Miller, Inorg. Chem. 2002, 41, 3599.

18 J. R. Galán-Mascarós, K. R. Dunbar, Chem. Commun. 2001, 217.

19 H. Grove, J. Sletten, M. Julve, F. Lloret, J. Chem. Soc., Dalton Trans. 2001, 1029.

20 P. S. Szalay, J. R. Galán,-Mascarós, B. L. Schottel, J. Basca, L. M. Pérez, A. S. Ichimura, A. Chouai, K. R. Dunbar, J. Clust. Sci. 2004, 15, 503.

21 S. P. Green, C. Jones, A. Stasch, Science 2007, 318, 1754.

22 M. Alfonso, H. Stoeckli-Evans, Acta Cryst 2001, E57, o242.

23 The geometry of the quartet state was also optimized without symmetry constraints, i.e. in $C_{1}$ symmetry, which yielded the same solution as with optimization in $C_{3}$ symmetry.
24 (a) A. D. Becke, Phys. Rev. A: At., Mol., Opt. Phys. 1988, 38, 3098. (b) C. Lee, W. Yang, and R. G. Parr, Phys. Rev. B: Condens. Matter Mater. Phys. 1988, 37, 785. (c) P. J. Stephens, F. J. Devlin, C. F. Chabalowski, M. J. J. Frisch, Phys. Chem. 1994, 98, 11623.G. Aragay, A. Frontera, V. Lloveras, J. Vidal-Gancedo, P. Ballester, J. Am. Chem. Soc. 2013, 135, 2620.

25 a) R. Krishnan, J.S. Binkley, R. Seeger and J.A. Pople, J. Chem. Phys. 1980, 72, 650. b) A.D. McLean and G.S. Chandler J. Chem. Phys. 1980, 72, 5639. c) J-P. Blaudeau, M. P. McGrath, L.A. Curtiss and L. Radom, J. Chem. Phys. 1997, 107, 5016.

26 F. Weigend, R. Ahlrichs, Phys. Chem. Chem. Phys. 2005, 7, 3297.

27 (a) W. Koch, M. C. Holthausen, A Chemist's Guide to Density Functional Theory, Wiley-VCH, Weinheim, $2^{\text {nd }}$ edn., 2001, pp 168. (b) M. Radon, Phys. Chem. Chem. Phys. 2014, 16, 14479.

28 B. E. Roos, P. R. Taylor, P. E. M. Siegbahn, Chem. Phys. 1980, 48, 157.

29 (a) P. Pulay and T. P. Hamilton, J. Chem. Phys. 1988, 88, 4926. (b) J. M. Bofill, P. Pulay, J. Chem. Phys. 1989, 89, 3637. (c) K Wolinski, P. Pulay, J. Chem. Phys. 1989, 90, 3647.

30 (a) A. I. Krylov, J. Phys. Chem. A. 2005, 109, 10638. (b) M. Winkler, W. Sander, Acc. Chem. Res. 2014, 47, 31.

31 a) L. V. Slipchenko, T. E. Munsch, P. G. Wenthold, A. I. Krylov, Angew. Chem. Int. Ed. 2004, 43, 742. b) A. M. C. Cristian, Y. Shao, A. I. Krylov, J. Phys. Chem. A 2004, 108, 6581.

32 P. Neuhaus, M. Winkler, W. Sander, J. Phys. Org. Chem. 2011, 24, 976.

33 H. M. T. Nguyen, T. T. Hue, M. T. Nguyen, Chem. Phys. Lett. 2005, $411,450$.

34 R. T. Boeré, T. Chivers, T. L. Roemmele, H. M. Tuononen, Inorg. Chem. 2009, 48, 7294.

35 Stable Radicals, (Ed.: R. G. Hicks), Wiley-VCH, Weinheim, 2010. 